\title{
K252a is highly effective in suppressing the growth of human endometrial cancer cells, but has little effect on normal human endometrial epithelial cells
}

\author{
NORIYUKI TAKAI, TAMI UEDA, MASAKAZU NISHIDA, \\ KAEI NASU and HISASHI NARAHARA
}

\author{
Department of Obstetrics and Gynecology, Oita University Faculty of Medicine, Japan
}

Received October 2, 2007; Accepted November 22, 2007

\begin{abstract}
The furanosylated indolocarbazole K252a belongs to a family of microbial alkaloids that also includes staurosporine, which is known to inhibit proliferation, stimulate apoptosis and induce the cell cycle arrest of cancer cells. To elucidate the involvement of K252a in endometrial cancer, we investigated the effects of $\mathrm{K} 252 \mathrm{a}$ on three endometrial cancer cell lines. Endometrial cancer cells were treated with $\mathrm{K} 252 \mathrm{a}$ and its effect on cell growth, cell cycle and related measurements was assessed. 3-(4,5-dimethylthiazol-2-yl)2,5-diphenyltetrazolium bromide assays showed that the endometrial cancer cell lines were sensitive to the growth inhibitory effect of K252a, although normal endometrial epithelial cells were viable after treatment with the same doses of K252a that induced the growth inhibition of endometrial cancer cells. Cell cycle analysis indicated that their exposure to K252a decreased the proportion of cells in the S phase and increased the proportion of cells in the G0/G1 phase of the cell cycle. TUNEL assays demonstrated that K252a induced apoptosis. This occurred in concert with an altered expression of $\mathrm{p} 21^{\mathrm{WAF} 1}$ and bcl-2 proteins related to the G0/G1 phase of the cell cycle and apoptosis. These results raise the possibility that K252a may prove to be particularly effective in the treatment of endometrial cancers.
\end{abstract}

\section{Introduction}

$\mathrm{K} 252 \mathrm{a}$ is a microbial alkaloid, an indolocarbazole derivative, isolated from the culture broth of the Nocardiopsis species. $\mathrm{K} 252 \mathrm{a}$ was initially isolated as a potent inhibitor of the $\mathrm{Ca}^{2+}$ messenger system and is a member of a family of related compounds (K252a, b, c and d) (1). These K252 compounds are structurally similar to staurosporine, which is known to

Correspondence to: Dr Noriyuki Takai, Department of Obstetrics and Gynecology, Oita University Faculty of Medicine, Hasamamachi, Yufu-shi, Oita 879-5593, Japan

E-mail: takai@med.oita-u.ac.jp

Key words: cell cycle, apoptosis, endometrial cancer inhibit glioma cell growth (2). The chemical structure of CBHA is shown in Fig. 1.

$\mathrm{K} 252 \mathrm{a}$ was found to inhibit protein kinase $\mathrm{C}(3,4)$, the cAMP- (3) and cGMP-dependent protein kinase (3), myosine light chain kinase (5), $\mathrm{Ca}^{2+} /$ calmodulin-dependent protein kinases (CaMKs) (6) and cell cycle regulatory kinases such as Cdc2 (7). Specifically, K252a blocks the nerve growth factor (NGF) and brain-derived neurotrophic factor (BDNF) activity in rat pheochromocytoma PC-12 and neuroblastoma cell lines by inhibiting TrkA and -B tyrosine kinase activity (8-10).

As previously reported, K252a inhibited the proliferation of human hepatoma cells by inducing G0/G1 arrest (11) and blocked the platelet-derived growth factor (PDGF) receptor in glioma cells and inhibited proliferation (12). It was shown to potently inhibit c-Met autophosphorylation, HGF-mediated cell scattering and c-Met-driven proliferation in gastric carcinoma cells. Moreover, it was reported to cause a reversion of tumorigenicity in fibroblasts transformed with an oncogenic form of c-Met (13). However, the effect of K252a on endometrial cancer cells has yet to be adequately described.

On the basis of these observations, we examined the effects of K252a on three endometrial cancer cell lines for the first time.

\section{Materials and methods}

Cell lines. The Ishikawa human endometrial cancer cell line was kindly provided by Dr Masato Nishida (Tsukuba University, Ibaraki, Japan). The HHUA human endometrial cancer cell line was obtained from Riken (Ibaraki, Japan) and the HEC-1B human endometrial cancer cell line was obtained from the American Type Culture Collection (Manassas, VA). The Ishikawa cells were maintained as monolayers at $37^{\circ} \mathrm{C}$ in $5 \% \mathrm{CO}_{2}$ /air in Dulbecco's modified Eagle's medium (DMEM) (Gibco, Rockville, MD) containing 5\% heat-inactivated fetal bovine serum (FBS) (Omega, Tarzana, CA). The other two cell lines were maintained as monolayers at $37^{\circ} \mathrm{C}$ in $5 \% \mathrm{CO}_{2} /$ air in Roswell Park Memorial Institute (RPMI)-1640 medium (Gibco) containing 10\% heat-inactivated FBS (Omega).

Normal endometrial epithelial cells. Normal endometrial specimens were obtained from ten pre-menopausal patients who had undergone hysterectomies for leiomyoma. All patients 


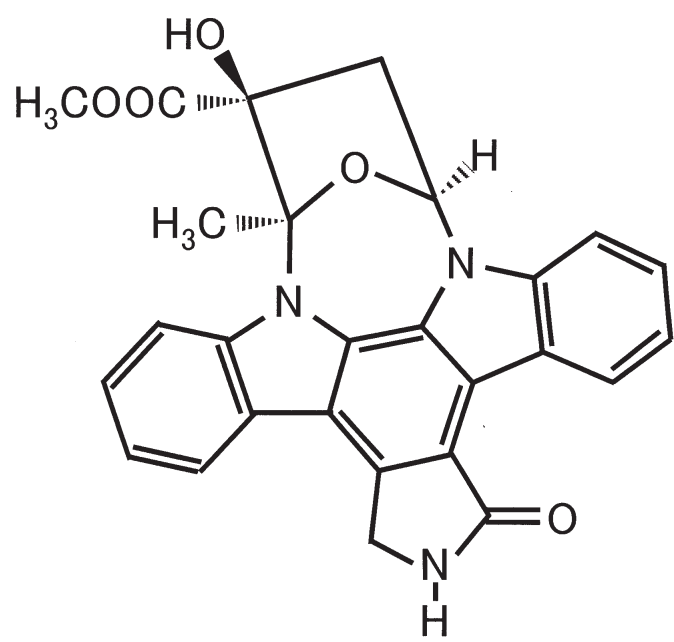

Figure 1. The chemical structure of K252a.

were free of any hormonal treatments before the operation. All of the specimens were diagnosed as being from the late proliferative phase (11th to 13th day of the menstrual cycle) using a standard histological examination of endometrial tissues. This study was approved by the institutional review board (IRB) of the Faculty of Medicine, Oita University and written informed consent was obtained from all patients.

Normal endometrial epithelial cells were separated from stromal cells by digesting the tissue fragments with collagenase. Briefly, the tissue was minced into 2- to 3-mm pieces and incubated with collagenase (200 U/ml) (Gibco) in RPMI1640 medium (Gibco) with stirring for $2 \mathrm{~h}$ at $37^{\circ} \mathrm{C}$. The suspension was then filtered through a $150-\mu \mathrm{m}$ wire sieve to remove mucus and undigested tissue. The filtrate was then passed through an $80-\mu \mathrm{m}$ wire sieve, which allowed the stromal cells to pass through while the intact glands were retained. After being washed three times with serum-free RPMI-1640, normal human endometrial epithelial cells were transferred to culture flasks (Corning, New York, NY) at a density of $10^{6}$ cells/ml in RPMI-1640 supplemented with $10 \%$ heat-inactivated FBS (Omega), streptomycin (100 $\mathrm{U} / \mathrm{ml})(\mathrm{Gibco})$ and penicillin $(100 \mathrm{U} / \mathrm{ml})(\mathrm{Gibco})$. After $16 \mathrm{~h}$, the attached cells, which were $>98 \%$ pure as analyzed by immunocytochemical staining with antibodies to keratin (Dako, Copenhagen, Denmark), vimentin (V9, Dako), factor VIII (Dako) and leukocyte common antigen (2B11+PD7/26, Dako), were used for the experiments. The cultures were incubated at $37^{\circ} \mathrm{C}$ in an atmosphere of $5 \% \mathrm{CO}_{2}$ in air at $100 \%$ humidity.

Chemicals. K252a was obtained from Calbiochem (San Diego, CA). K252a was dissolved in anhydrous dimethyl sulfoxide (DMSO) to a $100 \mathrm{mM}$ stock solution. Subsequent dilutions were made in $1 \mathrm{mM}$ fatty acid-free bovine serum albumin (BSA).

MTT assays. 3-(4,5-dimethylthiazol-2-yl)-2,5-diphenyltetrazolium bromide (MTT, Sigma) was placed in solution with PBS $(5 \mathrm{mg} / \mathrm{ml})$ and used to measure cellular proliferation. Cells $\left(1 \times 10^{3}\right)$ were incubated in $100 \mu 1$ of culture medium for
$72 \mathrm{~h}$ in 96-well plates and $10 \mu \mathrm{l}$ of an MTT solution was added. After $4 \mathrm{~h}$ incubation, $50 \mu \mathrm{l}$ of a solubilization solution (20\% SDS) was added and then cells were incubated at $37^{\circ} \mathrm{C}$ for $16 \mathrm{~h}$. In this assay, MTT is cleaved to an orange formazan dye by metabolically active cells. The dye was directly quantified using an enzyme-linked immunoabsorbent assay reader at $540 \mathrm{~nm}$.

Cell cycle analysis. Endometrial cancer cells $\left(5 \times 10^{4}\right)$ were exposed to $2 \times 10^{-6} \mathrm{M} \mathrm{K} 252 \mathrm{a}$ in six-well, flat-bottomed plates for 3 days. Total cells, both in suspension and adherent, were collected, washed and suspended in cold PBS. Cells were fixed in chilled $75 \%$ methanol and stained with propidium iodine. An analysis was performed immediately after staining using the CellFit program (Becton-Dickinson and Co.) whereby the $\mathrm{S}$ phase was calculated using an RFit model.

The measurement of apoptosis. DNA strand breaks were identified by a terminal deoxynucleotidyltransferase-mediated UTP end-labeling (TUNEL) technique using the in situ cell death detection kit as directed (Boehringer-Mannheim).

Western blot analysis. Cells were washed twice in PBS, suspended in lysis buffer [50 mM Tris (pH 8.0), $150 \mathrm{mM} \mathrm{NaCl}$, $0.1 \%$ SDS, $0.5 \%$ sodium deoxycholate, $1 \%$ NP40, phenylmethylsulfonyl fluoride at $100 \mu \mathrm{g} / \mathrm{ml}$, aprotinin at $2 \mu \mathrm{g} / \mathrm{ml}$, pepstatin at $1 \mu \mathrm{g} / \mathrm{ml}$ and leupeptin at $10 \mu \mathrm{g} / \mathrm{ml}$ ] and placed on ice for $30 \mathrm{~min}$. After centrifugation at $15,000 \mathrm{x} \mathrm{g}$ for $15 \mathrm{~min}$ at $4^{\circ} \mathrm{C}$, the suspension was collected. Protein concentrations were quantitated by using the Bio-Rad protein assay dye reagent concentrate (Bio-Rad Laboratories, Hercules, CA) according to the manufacturer's recommendations. Whole cell lysates $(40 \mu \mathrm{g})$ were resolved by SDS-PAGE in a 4-15\% gel, transferred to a polyvinylidene difuride membrane (Immobilon, Amersham Corp., Arlington Heights, IL) and probed sequentially with monoclonal antibodies against p2 $1^{\text {WAF1 }}$ (Ab-1, 1:1,000, Oncogene, San Diego, CA), bcl-2 (100, 1:1,000, Santa Cruz Biotechnology, Santa Cruz, CA), bax (N20, 1:1,000, Santa Cruz Biotechnology) and GAPDH (1:10,000, Research Diagnostics, Flanders, NJ). The blots were developed using the Supersignal West Pico chemiluminescent substrate kit (Pierce, Rockford, IL).

Statistical analysis. All numerical data were expressed as the average of the values obtained \pm SD. Statistical significance was determined by conducting a paired Student's t-test using STAT VIEW software (Abacus Concept, Berkeley, CA).

\section{Results}

The effects of $K 252 a$ on the proliferation and viability of the normal human endometrial epithelial cells and endometrial cancer cell lines in vitro. We examined the antitumor effects of K252a on the normal human endometrial epithelial cells and three endometrial cancer cell lines in vitro, using an MTT assay with an exposure of 2 days to the K252a (Fig. 2). Ishikawa, HHUA and HEC-1B endometrial cancer cells showed significant sensitivity to K252a with $1.5 \times 10^{-6}, 2.1 \times 10^{-6}$ and $18 \times 10^{-6} \mathrm{M}$, respectively, which caused a $50 \%$ inhibition (ED50) of their growth. On the other hand, the normal human 


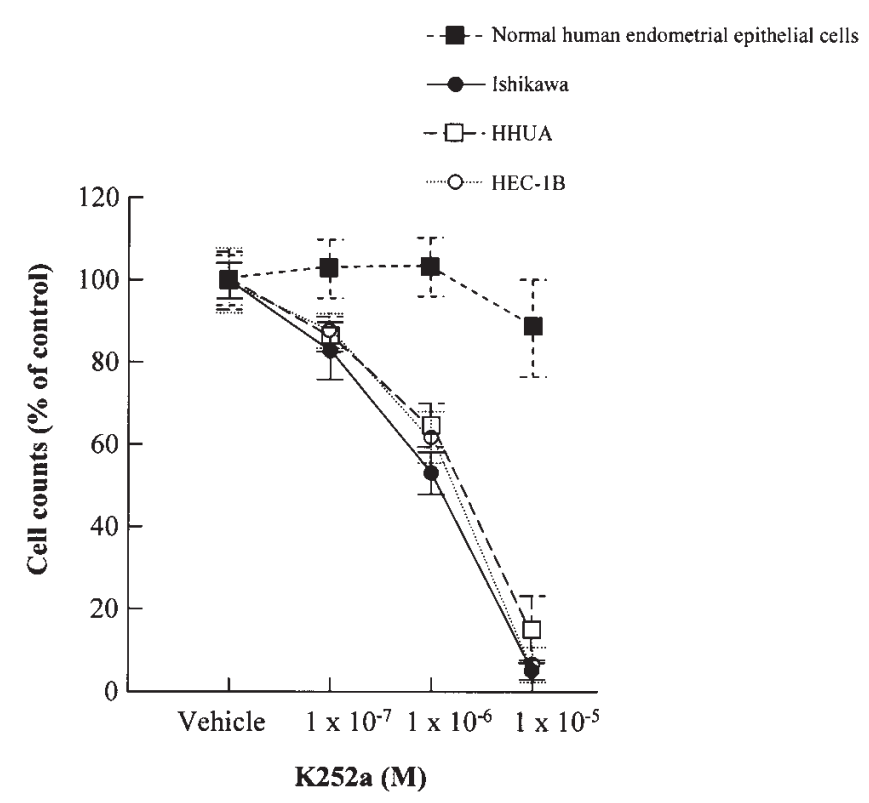

Figure 2. Effect of K252a on the growth of endometrial cancer cell lines and normal human endometrial epithelial cells in vitro. Three endometrial cancer cell lines and normal human endometrial epithelial cells were treated with either K252a at various concentrations $\left(1 \times 10^{-7}-1 \times 10^{-5} \mathrm{M}\right)$ or the dilutant (control) for $48 \mathrm{~h}$ and growth (\% of control) was measured by a 3-(4,5dimethylthiazol-2-yl)-2,5-diphenyltetrazolium bromide assay. The results represent the mean $\pm \mathrm{SD}$ of three independent experiments with triplicate dishes.

endometrial epithelial cells showed little sensitivity to K252a from $1.0 \times 10^{-7}$ to $1 \times 10^{-5} \mathrm{M}$.

The cell cycle analysis of ovarian cancer cells after exposure to $K 252 a$. Endometrial cancer cells cultured for 2 days in the presence of $\mathrm{K} 252 \mathrm{a}$ showed an accumulation in the G0/G1 phase $\left(2 \times 10^{-6} \mathrm{M}\right.$ of $\left.\mathrm{K} 252 \mathrm{a}\right)$ of the cell cycle, with a concomitant decrease in the proportion of those in the $\mathrm{S}$ phase. For example, a total of $52 \pm 7 \%$ of the untreated Ishikawa cells, compared with $79 \pm 0 \%$ of cells cultured with $2 \times 10^{-6} \mathrm{M}$ of K252a, were in the $\mathrm{G} 0 / \mathrm{G} 1$ phase. A total of $25 \pm 4 \%$ of the Ishikawa untreated cells, compared with $9 \pm 3 \%$ of cells cultured with $2 \times 10^{-6} \mathrm{M}$ of K252a were in the S phase (Fig. 3). This was representative of all the cell lines tested.

The effect of $\mathrm{K} 252 \mathrm{a}$ on the induction of apoptosis. The strong antiproliferative effect of $\mathrm{K} 252 \mathrm{a}$ on the endometrial cancer cells observed in vitro may be caused in part by the induction of apoptosis. To test this, we employed the TUNEL assay on the endometrial cancer cell lines treated with K252a for 2 days. As shown in Fig. 4, K252a induced apoptosis in a dosedependent manner, with $56 \%$ of the Ishikawa cells undergoing apoptosis after 2 days of being cultured with $2 \times 10^{-6} \mathrm{M} \mathrm{K252 \textrm {a }}$. The exposure of the three endometrial cancer cell lines to $\mathrm{K} 252 \mathrm{a}\left(2 \times 10^{-6} \mathrm{M}\right)$ for 2 days induced apoptosis in each [Ishikawa (56\%), HHUA (49\%) and HEC-1B cells (44\%)].

The effect of K252a on the expression of cell cycle-and apoptosis-related proteins. $\mathrm{p} 21^{\mathrm{WAF} 1}$ is one of the cyclindependent kinase inhibitors (CDKIs) that bind to cyclin-

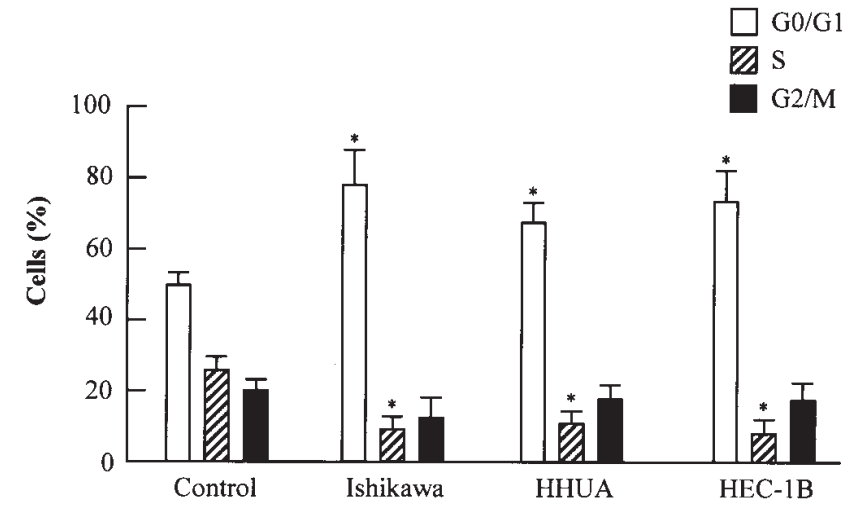

Figure 3. Cell-cycle analysis of endometrial cancer cells by flow cytometry. Endometrial cancer cells were cultured with K252a for $48 \mathrm{~h}$, harvested and stained with propidium iodine (PI). Control cells were treated with vehicle alone. Cell-cycle analysis was performed by flow cytometry (see Materials and methods). The results are presented as the mean \pm SD of three independent experiments; " $\mathrm{p}<0.05$ as determined by the Student's t-test, difference of the experimental versus the control group.

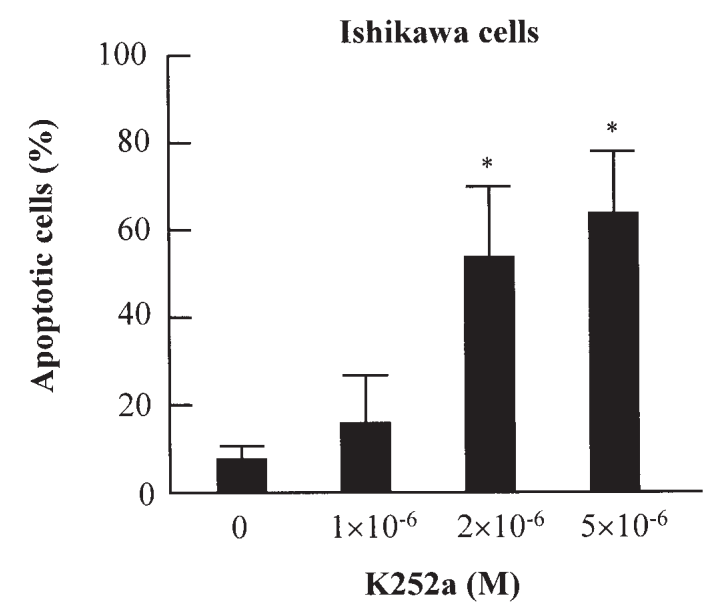

Figure 4. Induction of apoptosis by K252a. Endometrial cancer cells were treated for 2 days with different concentrations of K252a and then analyzed for apoptosis by TUNEL assay. The results are expressed as the mean \pm SD of three independent experiments; ${ }^{*} \mathrm{p}<0.05$ as determined by the Student's t-test and the difference versus the control group.

dependent kinase complexes and decrease kinase activity and may act as key regulators of the G0/G1 accumulation (14). We examined the effect of $\mathrm{K} 252 \mathrm{a}$ on the expression of $\mathrm{p} 21^{\mathrm{WAF} 1}$ in endometrial cancer cells by Western blot analysis (Fig. 5). K252a markedly up-regulated the level of the $\mathrm{p} 21^{\mathrm{WAF} 1}$ proteins, which were expressed at negligible levels in the untreated endometrial cancer cell lines.

Conversely, K252a decreased the levels of the bcl-2 expression in the endometrial cancer cells, whereas the Bax expression was unchanged (Fig. 5).

\section{Discussion}

We previously reported that the overexpression of CaMKIV in ovarian and endometrial cancer was associated with the 


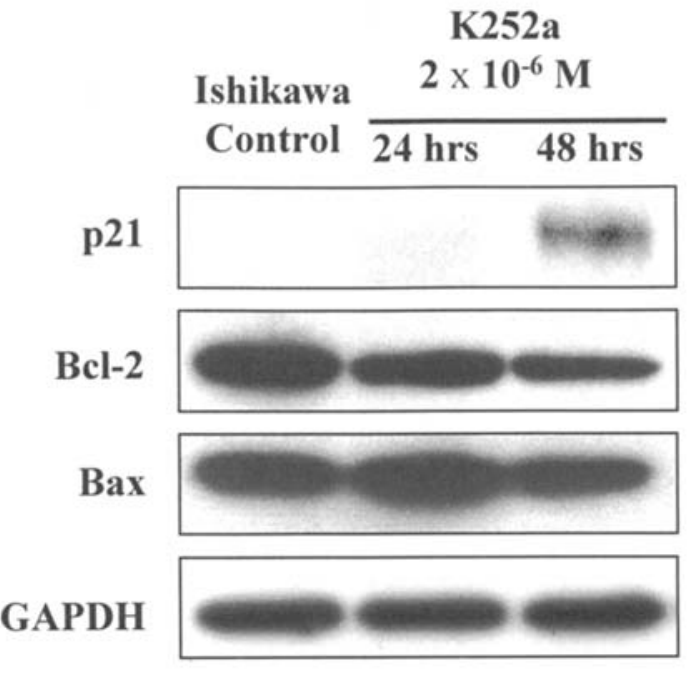

Figure 5. Cell cycle- and apoptosis-related protein expression in endometrial cancer cells, as measured by Western blot analysis. Endometrial cancer cells were treated with $2 \times 10^{-6}$ M K252a and cell lysates were harvested after 24 and $48 \mathrm{~h}$. Western blot analysis was performed with a series of antibodies. Control cells were treated with vehicle alone. The amount of protein was normalized by comparison to the levels of GAPDH.

malignant potential of these diseases $(15,16)$. CaMKs are known to phosphorylate microtubule-associated proteins, including the microtubule-associated protein 2 and $\tau$-factor, whose phosphorylation affects the microtubule assembly and actin filament cross-linking activity, respectively (17). CaMKs are involved in gene transcription factor phosphorylation $(3,18,19)$. Therefore, inhibition of the CaMK activity is associated with the onset of apoptosis. Treatment with CaMKselective inhibitors induces apoptosis in NIH3T3 cells (20) and sensitizes etoposide-resistant cells to the apoptotic challenge (21).

$\mathrm{K} 252 \mathrm{a}$ is a non-specific protein kinase inhibitor that is particularly effective as a CaMK inhibitor. K252a is a member of a group of natural (staurosporine, K252b) and synthetic (KT5720, KT5823 and KT5926) alkaloids that are thought to exert their biological activity by competing with the binding of ATP to the kinase catalytic domain $(3,4)$. It has been reported that K252a also inhibits the mitogen-activated protein (MAP) kinase, but its $50 \%$ inhibitory concentration is much higher for MAP kinase (22) than for CaMKs (6).

We have demonstrated that $\mathrm{K} 252 \mathrm{a}$ is highly effective in suppressing the growth of human endometrial cancer cells, although K252a has little effect on normal human endometrial epithelial cells.

We showed that K252a blocked the cell cycle of endometrial cancer cells at the G0/G1 phase. The up-regulation of p21 $1^{\mathrm{WAF} 1}$ by K252a provides an explanation for the K252ainduced G0/G1 block, because p2 $1^{\mathrm{WAF} 1}$ are cyclin-dependent kinase inhibitors that have important roles in blocking the cell cycle in the G0/G1 phase (22). K252a causes an increase in the expression of $\mathrm{p} 21^{\mathrm{WAF} 1}$, which probably contributes to the modulation of the activity of the downstream $\mathrm{pRb} / \mathrm{E} 2 \mathrm{~F}$ axis, triggering cell cycle arrest (23). Since Ishikawa, HHUA and HEC-1B cells express a mutant p53 protein, K252a appears to cause cell cycle arrest through p53-independent mechanisms.
Nakayama et al showed that K252a treatment did not alter the levels of cyclins D1, E and A or the Cdk2 protein bound to cyclins E or A (24). Future studies should define the specific sites and/or regulatory proteins of the cell cycle, except $\mathrm{p} 21^{\mathrm{WAF} 1}$, that are affected by K252a.

Apoptosis (programmed cell death) is an active genedirected mechanism of cellular suicide, important for the development and homeostasis of a multicellular organism. Specific therapies have been designed to enhance the susceptibility of human cancers when undergoing apoptosis. We demonstrated that treatment with K252a dramatically and significantly increased the number of apoptotic cells in all the endometrial cancer cell lines. This effect was associated with a decrease in the levels of the anti-apoptotic protein bcl-2.

In summary, K252a was shown to exhibit antiproliferative activity, potently induce cell cycle arrest and stimulate apoptosis in human endometrial cancer cells. These events are accompanied by the induction of $\mathrm{p} 21^{\mathrm{WAF} 1}$ and down-regulation of the anti-apoptosis-related protein, bcl-2. The effectiveness of an inhibitor such as K252a in modulating the kinase activity in vitro may hold therapeutic promise as a drug in the treatment of patients with endometrial cancer. K252a may represent a new class of agents for use in the treatment of endometrial cancer and certainly warrants further study.

\section{Acknowledgments}

The study was supported by a Grant-in-Aid (No. 16790961 to Noriyuki Takai) for Scientific Research from the Ministry of Education, Culture, Sports, Science and Technology, Japan.

\section{References}

1. Knusel B and Hefti F: K252a compounds: modulators of neurotrophin signal transduction. J Neurochem 59: 1987-1996, 1992.

2. Baltuch GH, Couldwell WT, Villemure J and Yong VW: Protein kinase $\mathrm{C}$ inhibitors suppress cell growth in established and lowpassage glioma cell lines: a comparison between staurosporine and tamoxifen. Neurosurgery 33: 495-501, 1993.

3. Kase H, Iwahashi K and Matsuda Y: K-252a, a potent inhibitor of protein kinase C from microbial origin. J Antibiot 39: 1059-1065, 1986.

4. Kase H, Iwahashi K, Nakanishi S, et al: K-252 compounds, novel and potent inhibitors of protein kinase $\mathrm{C}$ and cyclic nucleotidedependent protein kinases. Biochem Biophys Res Commun 142: 436-440, 1987.

5. Nakanishi S, Yamada K, Kase H, Nakamura S and Nonomura Y: K-252a, a novel microbial product, inhibits smooth muscle myosin light chain kinase. J Biol Chem 263: 6265-6219, 1988.

6. Hashimoto Y, Nakayama T, Teramoto T, et al: Potent and preferential inhibition of $\mathrm{Ca}^{2+} /$ calmodulin-dependent kinase II by K252a and its derivative, KT5926. Biochem Biophys Res Commun 181: 423-429, 1991.

7. Usui T, Yoshida M, Abe K, Osada H, Isono K and Beppu T: Uncoupled cell cycle without mitosis induced by protein kinase inhibitor, K252a. J Cell Biol 115: 1275-1282, 1991.

8. Koizumi S, Contreras ML, Matsuda Y, Hama T, Lazarovici P and Guroff G: K252a: A specific inhibitor of the action of nerve growth factor on PC12 cells. J Neurosci 8: 715-721, 1988.

9. Tapley P, Lamballe F and Barbacid M: K252a is a selective inhibitor of the tyrosine protein kinase activity of the trk family of oncogenes and neurotrophin receptors. Oncogene 7: 371-381, 1992.

10. Nye SH, Squinto SP, Glass DJ, et al: K252a and staurosporine selectively block autophosphorylation of neurotrophin receptors and neurotrophin-mediated responses. Mol Cell Biol 3: 677-686, 1992. 
11. Nakayama T, Hashimoto Y, Kaneko Y, et al: A new blocker of the cell-cycle at G1 phase in a human hepatoma cell line. Experientia 49: 876-880, 1993.

12. Chin LS, Murray SF, Zitnay KM and Rami B: K252a inhibits glioma proliferation by blocking PDGF signal transduction. Clin Cancer Res 3: 771-776, 1997.

13. Morotti A, Mila S, Accornero P, Tagliabue E and Ponzetto C: K252a inhibits the oncogenic properties of Met, the HGF receptor. Oncogene 21: 4885-4893, 2002.

14. Takai N, Desmond JC, Kumagai T, et al: Histone deacetylase inhibitors have a profound antigrowth activity in endometrial cancer cells. Clin Cancer Res 10: 1141-1149, 2004.

15. Takai N, Miyazaki T, Nishida M, Nasu K and Miyakawa I: $\mathrm{Ca}^{2+}$ /calmodulin-dependent kinase IV expression in epithelial ovarian cancer. Cancer Lett 183: 185-193, 2002.

16. Shang S, Takai N, Nishida M, Miyazaki T, Nasu K and Miyakawa I: CaMKIV expression is associated with clinical stage and PCNA-labeling index in endometrial carcinoma. Int J Mol Med 11: 181-186, 2003.

17. Yamamoto H, Fukunaga K, Goto S, Tanaka E and Miyamoto E: $\mathrm{Ca}^{2+} /$ calmodulin-dependent regulation of microtubule formation via phosphorylation of microtubule-associated protein 2 , tau factor, and tubulin, and comparison with the cyclic AMPdependent phosphorylation. J Neurochem 44: 759-768, 1985.

18. Enslen H, Sun P, Brickey D, Soderling SH, Klamo E and Soderling TR: Characterization of $\mathrm{Ca}^{2+} /$ calmodulin-dependent protein kinase IV. Role in transcriptional regulation. J Biol Chem 269: 15520-15527, 1994.
19. Enslen H, Tokumitsu H and Soderling TR: Phosphorylation of CREB by CaM-kinase IV activated by CaM-kinase IV kinase. Biochem Biophys Res Commun 207: 1038-1043, 1995.

20. Tombes RM, Grant S, Westin EH and Krystal G: G1 cell cycle arrest and apoptosis are induced in NIH 3T3 cells by KN-93, an inhibitor of CaMK-II (the multifunctional $\mathrm{Ca}^{2+} / \mathrm{CaM}$ kinase). Cell Growth Differ 6: 1063-1070, 1995.

21. Kawamura K, Grabowski D, Krivacic K, Hidaka H and Ganapathi R: Cellular events involved in the sensitization of etoposide-resistant cells by inhibitors of calcium-calmodulindependent processes. Role for effects on apoptosis, DNA cleavable complex, and phosphorylation. Biochem Pharmacol 52: 1903-1909, 1996.

22. Gotoh Y, Nishida E, Matsuda S, et al: In vitro effects on microtubule dynamics of purified Xenopus $M$ phase-activated MAP kinase. Nature 349: 251-254, 1991.

23. Freytag SO: Enforced expression of the c-myc oncogene inhibits cell differentiation by precluding entry into a distinct predifferentiation state in $\mathrm{G}_{0} / \mathrm{G}_{1}$. Mol Cell Biol 8: 1614-1624, 1988.

24. Nakayama T, Hashimoto Y, Kaneko Y and Kurokawa K: K252a inhibits the phosphorylation of $\mathrm{pRb}$ without changing the levels of G1 cyclins and Cdk2 protein in human hepatoma cells. Biochem Biophys Res Commun 224: 180-183, 1996. 